\title{
Myosin Light Chain Kinase: A Potential Target for Treatment of Inflammatory Diseases
}

\author{
Yongjian Xiong ${ }^{1+}$, Chenou Wang ${ }^{2 t}$, Liqiang Shi' ${ }^{2+}$, Liang Wang ${ }^{2}$, Zijuan Zhou ${ }^{2}$, \\ Dapeng Chen ${ }^{2 *}$, Jingyu Wang ${ }^{2 *}$ and Huishu Guo ${ }^{1 *}$
}

${ }^{1}$ Central Laboratory, The First Affiliated Hospital, Dalian Medical University, Dalian, China, ${ }^{2}$ Laboratory Animal Center, Dalian Medical University, Dalian, China

\section{OPEN ACCESS}

Edited by:

Salvatore Salomone,

University of Catania, Italy

Reviewed by:

Bashir M. Rezk,

Southern University at New Orleans,

United States

Andrea Huwiler,

University of Bern, Switzerland

*Correspondence:

Dapeng Chen

cdp.9527@163.com

Jingyu Wang

wangjingyus@163.com

Huishu Guo

guohuishu1@126.com

these authors have contributed

equally to this work.

Specialty section:

This article was submitted to

Experimental Pharmacology and Drug

Discovery,

a section of the journal

Frontiers in Pharmacology

Received: 02 January 2017 Accepted: 08 May 2017

Published: 23 May 2017

Citation:

Xiong $Y$, Wang $C$, Shi L, Wang L,

Zhou Z, Chen D, Wang J and Guo $H$

(2017) Myosin Light Chain Kinase:

A Potential Target for Treatment

of Inflammatory Diseases.

Front. Pharmacol. 8:292.

doi: 10.3389/fphar.2017.00292
Myosin light chain kinase (MLCK) induces contraction of the perijunctional apical actomyosin ring in response to phosphorylation of the myosin light chain. Abnormal expression of MLCK has been observed in respiratory diseases, pancreatitis, cardiovascular diseases, cancer, and inflammatory bowel disease. The signaling pathways involved in MLCK activation and triggering of endothelial barrier dysfunction are discussed in this review. The pharmacological effects of regulating MLCK expression by inhibitors such as ML-9, ML-7, microbial products, naturally occurring products, and microRNAs are also discussed. The influence of MLCK in inflammatory diseases starts with endothelial barrier dysfunction. The effectiveness of anti-MLCK treatment may depend on alleviation of that primary pathological mechanism. This review summarizes evidence for the potential benefits of anti-MLCK agents in the treatment of inflammatory disease and the importance of avoiding treatment-related side effects, as MLCK is widely expressed in many different tissues.

Keywords: myosin light chain kinase, inflammatory bowel diseases, cancer, tight junctions, endothelium

In mammals, myosin light chain kinase (MLCK) is encoded by the mylk 1 and $m y l k 2$ genes (Herring et al., 2006). mylk2 encodes an MLCK isoform that is exclusively expressed in skeletal muscle cells (Herring et al., 2006; Wang L. et al., 2016). Because of the lack of data on mylk2 gene coding products, we mainly discuss mylk1 gene products, which include long chain MLCK $(220 \mathrm{kDa})$, short chain MLCK (130 kDa), and the non-catalytic carboxy-terminal (17 kDa) protein, telokin (Chen et al., 2013; Chen C. et al., 2014; An et al., 2015). mylk1 gene coding products are expressed in diverse cell types and tissues including muscle, platelets, and secretory and brain cells (Jin et al., 2002). Numerous cell activities, such as contraction, adhesion, cell migration, and epithelial barrier formation occur in a myosin regulatory light chain (MLC) phosphorylation dependent or independent manner (Chen et al., 2013; Chen C. et al., 2014; Kim and Helfman, 2016). Abnormal expression of MLCK has been observed in many inflammatory diseases including pancreatitis (Shi et al., 2014), respiratory diseases (Zhou et al., 2015), cardiovascular diseases (Cheng et al., 2015), cancer (Zhou et al., 2014), and inflammatory bowel disease (IBD) (Yi et al., 2014). The involvement of MLCK and the MLCK signaling pathway that underlie representative inflammatory diseases is discussed. Some diseases in which MLCK is involved are listed in Table 1.

\section{MLCK IN RESPIRATORY DISEASES, ATHEROSCLEROSIS, AND PANCREATITIS}

In inflammatory lung disorders, damage to lung endothelial cell barrier integrity alters vascular permeability, and alveolar flooding often results (Mao et al., 2015). Abnormal expression of 
TABLE 1 | Role of myosin light chain kinase (MLCK) in selected diseases.

\begin{tabular}{|c|c|c|c|}
\hline Diseases & MLCK changes & MLCK isoform & Representative References \\
\hline Atherosclerosis & Increased expression & nmMLCK & Zhu et al., 2013 \\
\hline Hypertension & Increased activity & smMLCK & Cho et al., 2011 \\
\hline Heart injury/Heart failure & Increased activity & Cardiac MLCK & Lin et al., 2012; Chang et al., 2013 \\
\hline Glaucoma & Increased activity & smMLCK & Prayitnaningsih et al., 2016 \\
\hline Asthma & Increased expression/Gene variant & nmMLCK & Zhou et al., 2015 \\
\hline Lung inflammation/Lung injury & Increased expression /Gene variant & nmMLCK & Mirzapoiazova et al., 2009; Wu et al., 2011 \\
\hline Brain injury /Kidney injury & Increased expression & $\mathrm{nmMLCK}$ & Xu et al., 2015; Droylefaix et al., 2013 \\
\hline $\begin{array}{l}\text { Intestinal inflammation } \\
\text { /IBD/Barrier dysfunction }\end{array}$ & Increased expression & $\mathrm{nmMLCK}$ & Du et al., 2016; Jin and Blikslager, 2016; Xiong et al., 2016 \\
\hline Intestinal motility disorder & Increased/Decreased expression & smMLCK & Chen et al., 2015 \\
\hline Pancreatitis & Increased & $\mathrm{nmMLCK}$ & Shi et al., 2014 \\
\hline Prostate Cancer & - & $\mathrm{nmMLCK}$ & Spans et al., 2014 \\
\hline Breast cancer & - & $\mathrm{nmMLCK}$ & Kim and Helfman, 2016 \\
\hline Pancreatic cancer & - & $\mathrm{nmMLCK}$ & Kaneko et al., 2002 \\
\hline Non-small cell lung cancer & Increased & nmMLCK & Minamiya et al., 2005 \\
\hline Cervical cancer & - & nmMLCK & Shen et al., 2002 \\
\hline Gastric cancer & - & nmMLCK & Chen et al., 2016 \\
\hline
\end{tabular}

nmMLCK, non-muscle MLCK; smMLCK, smooth muscle MLCK.

MLCK occurs in lung injury, and the MLCK inhibitor ML-7 or deletion of the MLCK gene can attenuate lung injury (Wang T. et al., 2016). MLCK has similar activity in asthmatic and in lung inflammation, and variation of the MYLK gene is strongly associated with acute lung injury and asthma susceptibility (Wang et al., 2014, 2015; Wang T. et al., 2016).

MLCK-induced endothelial barrier dysfunction is also involved in pancreatitis and atherosclerosis (Cheng et al., 2015; Wang et al., 2014; Wang T. et al., 2016). Severe acute pancreatitis is associated with high morbidity and mortality. Its pathogenesis is not completely understood (Zerem, 2014), but MLCK expression is significantly increased in rat models of acute pancreatitis (Shi et al., 2014), and elevation of tumor necrosis factor (TNF) $\alpha$ in severe acute pancreatitis has been shown to mediate MLCK-dependent regulation of the cytoskeleton, leading to destruction of the endothelial barrier function (Shi et al., 2014; Yu et al., 2016). The initiation and development of atherosclerosis often leads to progressive vascular injury, which is accompanied by endothelial dysfunction (Phinikaridou et al., 2015). The involvement of MLCK in the natural history of atherosclerosis has been confirmed by alleviation of vascular injury and atherosclerosis by ML-7, an MLCK inhibitor (Cheng et al., 2015).

\section{MLCK IN CANCER DEVELOPMENT}

Abnormal expression of MLCK has been observed in pancreatic, lung, and prostate cancer cell lines (Tohtong et al., 2003; Nagaraj et al., 2010; Chen et al., 2011). Rapid, dynamic changes of the cytoskeleton are needed for invasion and metastasis of cancer cells. MLCK-dependent phosphorylation of cytoskeletal myosin II increases the metastatic potential of tumor cells, and MLCK-dependent cytoskeleton rearrangement modulates vascular endothelial barrier functions associated with angiogenesis, which is a critical step in cancer development (Dudek and Garcia, 2001). On the other hand, the metastatic potential of breast cancer cells is increased by the loss of MLCK (Kim and Helfman, 2016). Changes in cell migration and adhesion are also characteristic early steps in inflammation but there are few reports of MLCK regulation of inflammatory cell migration.

\section{MCLK IN IBD}

Inflammatory bowel disease, including ulcerative colitis and Crohn's disease, is characterized by chronic gastrointestinal inflammation, and is associated with significant patient impairment and high treatment costs (Rai et al., 2015). Although the pathogenesis of IBD remains obscure, there is evidence that intestinal barrier dysfunction is the primary driver (Hindryckx and Laukens, 2012; Pastorelli et al., 2015). Tight junction dysfunction leads to damage of the intestinal barrier, which permits passage of diverse pathogens (Jin and Blikslager, 2016). Tight junctions consist of transmembrane proteins such as occludins and claudins and peripheral membrane proteins, i.e., zonula occludens proteins (Van Itallie and Anderson, 2014). Tight junctions are located in the apicolateral region of endothelial cells and are bound to a perijunctional actomyosin ring. MLCK-induced phosphorylation of perijunctional actomyosin mediates tight junction loss, which can trigger the initiation and development of IBD. The expression and activity of MLCK is increased in human IBD and is associated with histological evidence of disease activity (Blair et al., 2006). Abnormal elevation of MLCK has also been observed in experimental colitis induced by gavage administration of dextran sulfate sodium or intracolonic administration of trinitrobenzenesulfonic acid (Su et al., 2013; Xiong et al., 2016). 


\section{MLCK Activation in IBD}

TNF- $\alpha$ is a proinflammatory cytokine that causes intestinal tight junction barrier dysfunction, which is central to IBD pathogenesis (Saleh et al., 2016). In IBD, TNF receptor 2 (R2)mediated signaling contributes to increased epithelial MLCK expression (Su et al., 2013; Suzuki et al., 2014). In a recent report by Al-Sadi et al. (2013), tight junction permeability of Caco-2 cell monolayers, in an in vitro model of intestinal epithelium, was increased by TNF- $\alpha$ activation of the ERK1/2 signaling pathway. Activation of the ERK1/2 pathway induced phosphorylation of ETS domain-containing transcription factor Elk-1. Activated Elk-1 then moved into the nucleus and bound to the MLCK promoter, finally resulting in epithelial MLCK expression. LIGHT (lymphotoxin-like inducible protein that competes with glycoprotein D for herpes virus entry on T cells) is a TNF core family member that is involved in the pathogenesis of human IBD (Krause et al., 2014), and in cultured epithelia, MLCK inhibition alleviated LIGHT-induced barrier loss, which suggested that LIGHT-induced epithelial barrier loss may depend on MLCK activation (Schwarz et al., 2007).

Increases in tight junction permeability through IL-1 $\beta$ mediated increases in MLCK expression has been demonstrated in inflammatory diseases (Beard et al., 2014). In mesenchymal stem cell migration, IL-1 $\beta$ was shown to cause an increase in epithelial MLCK expression through activation of the $\mathrm{PKCd} / \mathrm{NF}-\kappa \mathrm{B}$ pathway; it also stimulated MLCK activity via the $\mathrm{PKCa} / \mathrm{MEK} / \mathrm{ERK}$ signaling pathway (Lin et al., 2014).

IFN- $\gamma$ has also been associated with activation of MLCK by promoting adhesion and internalization of commensal bacteria by epithelial MLCK-activated brush border fanning (Wu et al., 2014). However, as with LIGHT-mediated regulation of MLCK, further study of INF- $\gamma$-mediated regulation of MLCK is needed to determine if it is direct. Signaling pathways associated with regulation of MLCK are shown in Supplementary Figure S1.

\section{MLCK-Associated Signaling Pathways That Can Trigger IBD}

In IBD, MLCK-induced epithelial barrier dysfunction is triggered by two signaling pathways. Firstly, in the gut, the epithelium forms a barrier against pathogens in the lumen. Abnormal expression of MLCK in inflammatory gastrointestinal diseases leads to phosphorylation of myosin II regulatory light chain (MLC), contraction of the actomyosin ring and increased intestinal permeability (Yi et al., 2015). Thus, MLCK-dependent MLC phosphorylation is an essential mechanism underlying MLCK-induced epithelial barrier dysfunction. A second mechanism involves MLCK-stimulated upregulation of claudin2 and occludin endocytosis (Su et al., 2013; Jin and Blikslager, 2016). Increased expression of claudin-2 has been associated with intestinal epithelial barrier dysfunction (Hu et al., 2015; Krishnan et al., 2015), as well as decreased absorption, leak flux diarrhea, and inflammatory responses (Hu et al., 2015). Down-regulation of occludin in IBD decreases gastrointestinal permeability, which may disrupt the integrity of the barrier against a variety of pathogens (Yin et al., 2015).

\section{Potential Pathological Role of Smooth Muscle MLCK in IBD}

Smooth muscle (sm) MLCK is transcribed from the same gene as epithelial MLCK. It is involved in the regulation of sm contraction, and variation of smMLCK content leads to motility disorders (Chen et al., 2015). The motility disorders secondarily cause abnormal growth of intestinal flora, which in turn aggravates the pathogenesis of intestinal inflammation (Chen D. et al., 2014; Welch et al., 2014). Whether there is a direct effect of smMLCK on inflammatory diseases needs further study.

\section{MLCK INHIBITORS WITH POTENTIAL PHARMACEUTICAL USE}

Myosin light chain kinase has catalytic, inhibitory, and calmodulin-binding domains (Chang et al., 2016). The activity of the catalytic domain can be disclosed by partial tryptic digestion, and can be blocked by MLCK inhibitors (Luck and Choh, 2011; Chang et al., 2016). MLCK inhibitors act by competitive binding at or near the ATP-binding site on the MLCK molecule (Saitoh et al., 1987; Luck and Choh, 2011). MLCK has been extensively studied in sm, but is widely distributed in animal cells and tissues. Consequently, determining the activities of MLCK in other tissues is critical; MLCK inhibitors are good tools for this. MLCK inhibitors also have pharmacological potential as vasodilators and anti-inflammatory agents. Some MLCK inhibitors, their origins and evidence of pharmacological effect are listed in Table 2.

\section{ML-9 and ML-7}

ML-9 [1-(5-chloronaphthalene-1-sulfonyl)-1H-hexahydro-1,4diazepine] is a classical MLCK inhibitor $\left(\mathrm{IC}_{50}=3.8 \mu \mathrm{M}\right)$, which was found to inhibit both $\mathrm{Ca}^{2+}$-calmodulin-dependent and -independent smMLCK (Saitoh et al., 1987; Shi et al., 2007). Both ML-9 and its synthetic derivatives are good selective inhibitors of smMLCK (Ito et al., 2004). ML-9 has been shown to reduce intraocular pressure in rabbit eyes (Honjo et al., 2002).

Another MLCK inhibitor, ML-7 [1-(5-iodonaphthalene-1sulphonyl) $1 \mathrm{H}$-hexahydro 1, 4-diazepine hydrochloride], is a membrane-permeable agent (Shi et al., 2007). Both ML-9 and ML-7 are naphthalene sulfonamide derivatives (Shi et al., 2007). ML-7 inhibition is more than 30-fold more potent than that of ML-9 $\left(\mathrm{IC}_{50}=300 \mathrm{nM}\right)$ (Shi et al., 2007). However, compared with ML-9, specific MLCK inhibition of smMLCK and other MLCK isoforms may be less potent (Saitoh et al., 1987). Beneficial effects of ML-7 has been shown in many conditions including heart ischemia/reperfusion injury (Lin et al., 2012; Zhang et al., 2015), IBD (Cheng et al., 2015), and atherosclerosis (Cheng et al., 2015).

\section{Microbial Product Inhibitors of MLCK}

K-252a, a microbial alkaloid purified from microbial cultures, is a non-selective inhibitor of MLCK (Nakanishi et al., 1992) as well as other protein kinases including protein kinase $\mathrm{C}$ and some cyclic nucleotide-dependent protein kinases (Nakanishi et al., 1992). KT592 is a derivative of K-252a with increased selectivity. Wortmannin, isolated and purified from the fungal 
TABLE 2 | Myosin light chain kinase inhibitors with potential pharmaceutical use.

\begin{tabular}{|c|c|c|c|}
\hline Name & Source & Inhibited MLCK isoform & Disease or condition \\
\hline ML-9 & Synthetic & nmMLCK, smMLCK & High blood pressure (Honjo et al., 2002). \\
\hline ML-7 & Synthetic & nmMLCK, smMLCK & $\begin{array}{l}\text { Heart ischemia/reperfusion injury (Lin et al., 2012; Zhang et al., 2015), } \\
\text { IBD (Cheng et al., 2015), and atherosclerosis (Cheng et al., 2015). }\end{array}$ \\
\hline$K-252 a$ & Microbial culture & nmMLCK, smMLCK & - \\
\hline KT592 & Microbial culture & nmMLCK, smMLCK & - \\
\hline Wortmannin & Microbial culture & NmMLCK, smMLCK & - \\
\hline Quercetin & Natural source & SmMLCK & Gut hyper motility (Zhang et al., 2006) \\
\hline Genistin & Natural source & smMLCK & Intestinal hyper motility (Xiong et al., 2013) \\
\hline Wogonin & Natural source & nmMLCK & $\begin{array}{l}\text { Diseases associated with the development of both inflammatory and } \\
\text { tumor (Huang et al., 2015) }\end{array}$ \\
\hline Capsaicin & Natural source & smMLCK, nmMLCK & Intestinal motility disorder (Chen et al., 2015) \\
\hline Salvianolic acid B & Natural source & NmMLCK & IBD (Xiong et al., 2016) \\
\hline Lithium & Natural source & smMLCK & Intestinal hyper motility (Tang et al., 2010) \\
\hline
\end{tabular}

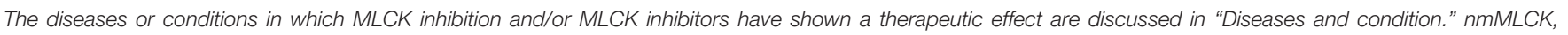
non-muscle MLCK; smMLCK, smooth muscle MLCK.

strain Talaromyces wortmannin KY12420, is another microbial product inhibitor of MLCK (Nakanishi et al., 1992), It has been shown to decrease secretory responses in rat adrenal medullary cells through inhibition of MLCK (Warashina, 2000) and to have antifungal, hemorrhagic, and anti-inflammatory activity that may not be related to inhibition of MLCK (Nakanishi et al., 1992). The potential pharmacological effects of these inhibitors warrant further study.

\section{Naturally Occurring Potential Inhibitors of MLCK}

As shown in Table 2, some naturally occurring bioactive constituents may be inhibitors of MLCK. In an in vitro system including purified myosin and MLCK, quercetin inhibited myosin phosphorylation. The inhibition can be blocked by the MLCK inhibitor ML-7, indicating that quercetin may be a direct MLCK inhibitor (Zhang et al., 2006). In an animal model of gut motility disorder, capsaicin administration significantly decreased MLCK expression, which also implicates MLCK as a target for inhibition by capsaicin (Chen et al., 2015). The inhibition in response to salvianolic acid B may be indirect; other signaling is involved. Salvianolic acid B decreases MLCK expression by upregulation of microRNA1 (Xiong et al., 2016). Upregulation of microRNA-374a, microRNA-155, miR-520c$3 \mathrm{p}$, and miR-1290 has also been found to reduce MLCK expression in various tissues (Adyshev et al., 2013; Weber et al., 2014). Naturally occurring bioactive compounds that act indirectly through microRNAs are an alternative inhibition pathway. However, disease-specific pharmacological experiments are needed to confirm the effects of potential naturally occurring inhibitors of MLCK.

\section{SUMMARY}

This review summarizes the evidence for a role of MLCK in inflammatory diseases, especially IBD. Abnormal expression of MLCK is involved in diverse pathological events, mainly by causing cytoskeletal changes that disrupt epithelial barrier function. The effect of anti-MLCK agents in specific inflammatory diseases depends on the extent to which endothelial function is involved. Prevention of treatmentrelated side effects is a key consideration because MLCK is abundantly expressed in many tissues. Consideration of two aspects of selectivity helps to anticipate and prevent side effects of MLCK inhibitors. First is the selective inhibition of MLCK and other protein kinases such as protein kinase $\mathrm{C}$ and cyclic nucleotide-dependent protein kinase; the other is selective inhibition of the different MLCK isoforms such as smMLCK and nmMLCK. Potential anti-MLCK pharmaceutical agents offer a novel insight into the treatment of inflammatory diseases that differs from traditional anti-inflammatory therapy.

\section{AUTHOR CONTRIBUTIONS}

Conceived and designed the review: DC. References check: DC, YX, CW, LW, ZZ, and LS. Drafted the paper and revised it critically for important intellectual content: DC, YX, CW, LW, $\mathrm{ZZ}$, and LS. The manuscript has been approved by all the authors.

\section{ACKNOWLEDGMENTS}

This study was supported by National Natural Science Foundation of China (grant number 81600440, 81273919) and Dalian Municipal Medical Research Foundation.

\section{SUPPLEMENTARY MATERIAL}

The Supplementary Material for this article can be found online at: http://journal.frontiersin.org/article/10.3389/fphar.2017. 00292/full\#supplementary-material

FIGURE S1 | Mechanisms underlying MLCK-induced regulation of the endothelial barrier function are shown. Solid arrows indicate direct interaction and dotted arrows indicate indirect interactions. 


\section{REFERENCES}

Adyshev, D. M., Moldobaeva, N., Mapes, B., Elangovan, V., and Garcia, J. G. (2013). MicroRNA regulation of nonmuscle myosin light chain kinase expression in human lung endothelium. Am. J. Respir. Cell Mol. Biol. 49, 58-66. doi: 10.1165/ rcmb.2012-0397OC

Al-Sadi, R., Guo, S., Ye, D., and Ma, T. Y. (2013). TNF- $\alpha$ modulation of intestinal epithelial tight junction barrier is regulated by ERK1/2 activation of Elk-1. Am. J. Pathol. 183, 1871-1884. doi: 10.1016/j.ajpath.2013.09.001

An, C., Bhetwal, B. P., Sanders, K. M., Somlyo, A. V., and Perrino, B. A. (2015). Role of telokin in regulating murine gastric fundus smooth muscle tension. PLoS ONE 10:e0134876. doi: 10.1371/journal.pone.0134876

Beard, R. J., Haines, R. J., Wu, K. Y., Reynolds, J. J., Davis, S. M., Elliott, J. E., et al. (2014). Non-muscle Mlck is required for $\beta$-catenin- and FoxO1dependent downregulation of Cldn 5 in IL-1 $\beta$-mediated barrier dysfunction in brain endothelial cells. J. Cell Sci. 127, 1840-1853. doi: 10.1242/jcs.144550

Blair, S. A., Kane, S. V., Clayburgh, D. R., and Turner, J. R. (2006). Epithelial myosin light chain kinase expression and activity are upregulated in inflammatory bowel disease. Lab. Invest. 86, 191-201. doi: 10.1038/labinvest.3700373

Chang, A. N., Huang, J., Battiprolu, P. K., Hill, J. A., Kamm, K. E., and Stull, J. T. (2013). The effects of neuregulin on cardiac myosin light chain kinase gene-ablated hearts. PLoS ONE 8:e66720. doi: 10.1371/journal.pone.0066720

Chang, A. N., Mahajan, P., Knapp, S., Barton, H., Sweeney, H. L., Kamm, K. E., et al. (2016). Cardiac myosin light chain is phosphorylated by Ca2+/calmodulindependent and -independent kinase activities. Proc. Natl. Acad. Sci. U.S.A. 113, E3824-E3833. doi: 10.1073/pnas.1600633113

Chen, C., Tao, T., Wen, C., He, W. Q., Qiao, Y. N., Gao, Y. Q., et al. (2014). Myosin light chain kinase (MLCK) regulates cell migration in a myosin regulatory light chain phosphorylation-independent mechanism. J. Biol. Chem. 289, 28478-28488. doi: 10.1074/jbc.M114.567446

Chen, D., Xiong, Y., Lin, Y., Tang, Z., Wang, J., Wang, L., et al. (2015). Capsaicin alleviates abnormal intestinal motility through regulation of enteric motor neurons and MLCK activity: relevance to intestinal motility disorders. Mol. Nutr. Food Res. 59, 1482-1490. doi: 10.1002/mnfr.201500039

Chen, D., Yuan, L., and Xiong, Y. (2014). Epithelial MLCK and smooth muscle MLCK may play different roles in the development of inflammatory bowel disease. Dig. Dis. Sci. 59, 1068-1069. doi: 10.1007/s10620-014-3101-y

Chen, M., Zhang, W., Lu, X., Hoggatt, A. M., Gunst, S. J., Kassab, G. S., et al. (2013). Regulation of $130-\mathrm{kDa}$ smooth muscle myosin light chain kinase expression by an intronic CArG element. J. Biol. Chem. 288, 34647-34657. doi: 10.1074/jbc. M113.510362

Chen, Q. Y., Xu, L. Q., Jiao, D. M., Yao, Q. H., Wang, Y. Y., Hu, H. Z., et al. (2011). Silencing of Racl modifies lung cancer cell migration, invasion and actin cytoskeleton rearrangements and enhances chemosensitivity to antitumor drugs. Int. J. Mol. Med. 28, 769-776. doi: 10.3892/ijmm.2011.775

Chen, Z., Liu, S., Xia, Y., and Wu, K. (2016). MiR-31 regulates Rho-associated kinase-myosin light chain (ROCK-MLC) pathway and inhibits gastric cancer invasion: roles of RhoA. Med. Sci. Monit. 22, 4679-4691. doi: 10.12659/MSM. 898399

Cheng, X., Wang, X., Wan, Y., Zhou, Q., Zhu, H., and Wang, Y. (2015). Myosin light chain kinase inhibitor ML7 improves vascular endothelial dysfunction via tight junction regulation in a rabbit model of atherosclerosis. Mol. Med. Rep. 12, 4109-4116. doi: 10.3892/mmr.2015.3973

Cho, Y. E., Ahn, D. S., Morgan, K. G., and Lee, Y. H. (2011). Enhanced contractility and myosin phosphorylation induced by $\mathrm{Ca}^{2+}$-independent MLCK activity in hypertensive rats. Cardiovasc. Res. 91, 162-170. doi: 10.1093/cvr/cvr043

Droylefaix, M. T., Bueno, L., Caron, P., Belot, E., and Roche, O. (2013). Ocular inflammation and corneal permeability alteration by benzalkonium chloride in rats: a protective effect of a myosin light chain kinase inhibitor. Invest. Ophthalmol. Vis. Sci. 54, 2705-2710. doi: 10.1167/iovs.12-10193

Du, L., Kim, J. J., Shen, J., and Dai, N. (2016). Crosstalk between inflammation and ROCK/MLCK signaling pathways in gastrointestinal disorders with intestinal hyperpermeability. Gastroenterol. Res. Pract. 2016:7374197. doi: 10.1155/2016/ 7374197

Dudek, S. M., and Garcia, J. G. N. (2001). Cytoskeletal regulation of pulmonary vascular permeability. J. Appl. Physiol. 91, 1487-1500.

Herring, B. P., Elmounayri, O., Gallagher, P. J., Yin, F., and Zhou, J. (2006). Regulation of myosin light chain kinase and telokin expression in smooth muscle tissues. Am. J. Physiol. Cell Physiol. 291, C817-C827. doi: 10.1152/ ajpcell.00198.2006

Hindryckx, P., and Laukens, D. (2012). "Intestinal barrier dysfunction: the primary driver of IBD?," in Inflammatory Bowel Disease Advances in Pathogenesis \& Management, (Rijeka: In-Tech), 23-40.

Honjo, M., Inatani, M., Kido, N., Sawamura, T., Yue, B. Y. J. T., Honda, Y., et al. (2002). A myosin light chain kinase inhibitor, ML-9, lowers the intraocular pressure in rabbit eyes. Exp. Eye Res. 75, 135-142. doi: 10.1006/exer. 2002.2009

Hu, C. A. A., Hou, Y., Yi, D., Qiu, Y., Wu, G., Kong, X., et al. (2015). Autophagy and tight junction proteins in the intestine and intestinal diseases. Anim. Nutr. 1, 123-127. doi: 10.1016/j.aninu.2015.08.014

Huang, Y., Luo, X., Li, X., Song, X., Wei, L., Li, Z., et al. (2015). Wogonin inhibits LPS-induced vascular permeability via suppressing MLCK/MLC pathway. Vasc. Pharmacol. 72, 43-52. doi: 10.1016/j.vph.2015.04.012

Ito, S., Kume, H., Honjo, H., Kodama, I., Katoh, H., Hayashi, H., et al. (2004). ML-9, a myosin light chain kinase inhibitor, reduces intracellular $\mathrm{Ca}^{2+}$ concentration in guinea pig trachealis. Eur. J. Pharmacol. 486, 325-333. doi: 10.1016/j.ejphar. 2004.01.013

Jin, Y., and Blikslager, A. T. (2016). Myosin light chain kinase mediates intestinal barrier dysfunction via occludin endocytosis during anoxia/reoxygenation injury. Am. J. Physiol. Cell Physiol. 311, C996-C1004. doi: 10.1152/ajpcell.00113. 2016

Jin, Y., Hou, L., and Dixon, S. A. (2002). 220- and 130-kDa MLCKs have distinct tissue distributions and intracellular localization patterns. Am. J. Physiol. Cell Physiol. 282, C451-C460.

Kaneko, K., Satoh, K., Masamune, A., Satoh, A., and Shimosegawa, T. (2002). Myosin light chain kinase inhibitors can block invasion and adhesion of human pancreatic cancer cell lines. Pancreas 24, 34-41. doi: 10.1097/00006676200201000-00005

Kim, D. Y., and Helfman, D. M. (2016). Loss of MLCK leads to disruption of cell-cell adhesion and invasive behavior of breast epithelial cells via increased expression of EGFR and ERK/JNK signaling. Oncogene 43, 50-57. doi: 10.1038/ onc.2015.508

Krause, P., Zahner, S. P., Kim, G., Shaikh, R. B., Steinberg, M. W., and Kronenberg, M. (2014). The tumor necrosis factor family member TNFSF14 (LIGHT) is required for resolution of intestinal inflammation in mice. Gastroenterology 146, 1752-1762. doi: 10.1053/j.gastro.2014.02.010

Krishnan, M., Sayoc, A., and Mccole, D. (2015). PTPN2 gene deficiency leads to increased epithelial permeability and promotes STAT-1-dependent Claudin-2 expression. FASEB J. 29(Suppl. 1), 998.

Lin, C. Y., Zu, C. H., Yang, C. C., Tsai, P. J., Shyu, J. F., Chen, C. P., et al. (2014). IL-1 $\beta$-induced mesenchymal stem cell migration involves MLCK activation via PKC signaling. Cell Transplant. 24, 2011-2028. doi: 10.3727/ 096368914 X685258

Lin, H. B., Cadete, V. J. J., Sawicka, J., Wozniak, M., and Sawicki, G. (2012). Effect of the myosin light chain kinase inhibitor ML-7 on the proteome of hearts subjected to ischemia-reperfusion injury. J. Proteomics 75, 5386-5395. doi: 10.1016/j.jprot.2012.06.016

Luck, S., and Choh, V. (2011). Effects of a myosin light chain kinase inhibitor on the optics and accommodation of the avian crystalline lens. Mol Vis. 17, 2759-2764.

Mao, S. Z., Ye, X., Liu, G., Song, D., and Liu, S. F. (2015). Resident endothelial cells and endothelial progenitor cells restore endothelial barrier function after inflammatory lung injury. Arterioscler. Thromb. Vasc. Biol. 35, 1635-1644. doi: 10.1161/ATVBAHA.115.305519

Minamiya, Y., Nakagawa, T., Saito, H., Matsuzaki, I., Taguchi, K., Ito, M., et al. (2005). Increased expression of myosin light chain kinase mRNA is related to metastasis in non-small cell lung cancer. Tumor Biol. 26, 153-157. doi: 10.1159/000086487

Mirzapoiazova, T., Moitra, J., Sammani, S., Mambetsariev, B., Chiang, E. T., Evenovski, C., et al. (2009). Critical role for non-muscle MLCK in ventilatorinduced lung injury (VILI). J. Investig. Med. 179, 529-530. doi: 10.1164/ajrccmconference.2009.179.1_meetingabstracts.a3822

Nagaraj, N. S., Smith, J. J., Revetta, F., Washington, M. K., and Merchant, N. B. (2010). Targeted inhibition of Src kinase signaling attenuates pancreatic tumorigenesis. Mol. Cancer Ther. 9, 2322-2332. doi: 10.1158/1535-7163.MCT$09-1212$ 
Nakanishi, S., Kakita, S., Takahashi, I., Kawahara, K., Tsukuda, E., Sano, T., et al. (1992). Wortmannin, a microbial product inhibitor of myosin light chain kinase. J. Biol. Chem. 267, 2157-2163.

Pastorelli, L., Dozio, E., Pisani, L. F., Boscoloanzoletti, M., Vianello, E., Munizio, N., et al. (2015). Procoagulatory state in inflammatory bowel diseases is promoted by impaired intestinal barrier function. Gastroenterol. Res. Pract. 2015:189341. doi: $10.1155 / 2015 / 189341$

Phinikaridou, A., Andia, M. E., Plaza, B. L., Saha, P., Smith, A., and Botnar, R. (2015). Increased vascular permeability is a surrogate marker of atherosclerotic plaque instability. J. Cardiovasc. Magn. Reson. 17(Suppl. 1):Q111. doi: 10.1186/ 1532-429x-17-s1-q111

Prayitnaningsih, S., Sujuti, H., Effendi, M., Abdullah, A., Anandita, N. W., Yohana, F., et al. (2016). Neuropathy optic glaucomatosa induced by systemic hypertension through activation endothelin-1 signaling pathway in central retinal artery in rats. Int. J. Ophthalmol. 9, 1568-1577.

Rai, T., Wu, X., and Shen, B. (2015). Frequency and risk factors of low immunoglobulin levels in patients with inflammatory bowel disease. Gastroenterol. Rep. 3, 115-121. doi: 10.1093/gastro/gou082

Saitoh, M., Ishikawa, T., Matsushima, S., Naka, M., and Hidaka, H. (1987). Selective inhibition of catalytic activity of smooth muscle myosin light chain kinase. J. Biol. Chem. 262, 7796-7801.

Saleh, A. M. E., Al-Robayan, A. A., Mubarak, A. O. M., Misbahul, A., and AlAsmari, A. K. (2016). Association of tumor necrosis factor- $\alpha$ and $-\beta$ gene polymorphisms in inflammatory bowel disease. J. Inflamm. Res. 9, 133-140. doi: 10.2147/JIR.S101225

Schwarz, B. T., Wang, F., Shen, L., Clayburgh, D. R., Su, L., Wang, Y., et al. (2007). LIGHT signals directly to intestinal epithelia to cause barrier dysfunction via cytoskeletal and endocytic mechanisms. Gastroenterology 132, 2383-2394. doi: 10.1053/j.gastro.2007.02.052

Shen, M. R., Furla, P., Chou, C. Y., and Ellory, J. C. (2002). Myosin light chain kinase modulates hypotonicity-induced $\mathrm{Ca}^{2+}$ entry and $\mathrm{Cl}^{-}$channel activity in human cervical cancer cells. Eur. J. Physiol. 444, 276-285. doi: 10.1007/s00424002-0811-3

Shi, H. R., Tang, G. D., Qin, M. B., and He, J. P. (2014). Expression of MLCK in severe acute pancreatitis in rats. World Chin. J. Digestol. 22, 3904-3910. doi: 10.1016/j.kjms.2016.07.008

Shi, J., Takahashi, S., Jin, X. H., Li, Y. Q., Ito, Y., Mori, Y., et al. (2007). Myosin light chain kinase-independent inhibition by ML-9 of murine TRPC6 channels expressed in HEK293 cells. Br. J. Pharmacol. 152, 122-131. doi: 10.1038/sj.bjp. 0707368

Spans, L., Helsen, C., Clinckemalie, L., Broeck, T. V. D., Prekovic, S., Joniau, S., et al. (2014). Comparative genomic and transcriptomic analyses of LNCaP and C4-2B prostate cancer cell lines. PLoS ONE 9:e90002. doi: 10.1371/journal.pone. 0090002

Su, L., Nalle, S., Shen, L., Turner, E., Singh, G., Breskin, L., et al. (2013). TNFR2 activates MLCK-dependent tight junction dysregulation to cause apoptosismediated barrier loss and experimental colitis. Gastroenterology 145, 407-415. doi: 10.1053/j.gastro.2013.04.011

Suzuki, M., Nagaishi, T., Yamazaki, M., Onizawa, M., Watabe, T., Sakamaki, Y., et al. (2014). Myosin light chain kinase expression induced via tumor necrosis factor receptor 2 signaling in the epithelial cells regulates the development of colitis-associated carcinogenesis. PLoS ONE 9:e88369. doi: 10.1371/journal. pone.0088369

Tang, Z. Y., Liu, Z. N., Fu, L., Chen, D. P., Ai, Q. D., and Lin, Y. (2010). Effect of lithium on smooth muscle contraction and phosphorylation of myosin light chain by MLCK. Physiol. Res. 59, 919-926.

Tohtong, R., Phattarasakul, K., Jiraviriyakul, A., and Sutthiphongchai, T. (2003). Dependence of metastatic cancer cell invasion on MLCK-catalyzed phosphorylation of myosin regulatory light chain. Prostate Cancer Prostatic Dis. 6, 212-216. doi: 10.1038/sj.pcan.4500663

Van Itallie, C. M., and Anderson, J. M. (2014). Architecture of tight junctions and principles of molecular composition. Semin. Cell Dev. Biol. 36, 157-165. doi: 10.1016/j.semcdb.2014.08.011

Wang, L., Zuo, L., Hu, J., Shao, H., Lei, C., Qi, W., et al. (2016). Dual LQT1 and HCM phenotypes associated with tetrad heterozygous mutations in KCNQ1, MYH7, MYLK2, and TMEM70 genes in a three-generation Chinese family. Europace 18, 602-609. doi: 10.1093/europace/euv043
Wang, T., Mathew, B., Wu, X., Shimizu, Y., Rizzo, A. N., Dudek, S. M., et al. (2016). Nonmuscle myosin light chain kinase activity modulates radiation-induced lung injury. Pulm. Circ. 6, 234-239. doi: 10.1086/686491

Wang, T., Moreno-Vinasco, L., Ma, S. F., Zhou, T., Shimizu, Y., Sammani, S., et al. (2014). Nonmuscle myosin light chain kinase regulates murine asthmatic inflammation. Am. J. Respir. Cell Mol. Biol. 50, 1129-1135. doi: 10.1165/rcmb. 2013-0434OC

Wang, T., Zhou, T., Saadat, L., and Garcia, J. G. (2015). A MYLK variant regulates asthmatic inflammation via alterations in mRNA secondary structure. Eur. J. Hum. Genet. 23, 874-876. doi: 10.1038/ejhg.2014.201

Warashina, A. (2000). Mechanism of wortmannin-induced inhibition of secretory responses in rat adrenal medullary cells. Life Sci. 67, 2587-2593. doi: 10.1016/ S0024-3205(00)00842-0

Weber, M., Kim, S., Patterson, N., Rooney, K., and Searles, C. D. (2014). MiRNA-155 targets myosin light chain kinase and modulates actin cytoskeleton organization in endothelial cells. Am. J. Physiol. Heart Circ. Physiol. 306, 1192-1203. doi: 10.1152/ajpheart.00521.2013

Welch, M. G., Margolis, K. G., Li, Z., and Gershon, M. D. (2014). Oxytocin regulates gastrointestinal motility, inflammation, macromolecular permeability, and mucosal maintenance in mice. Am. J. Physiol. Gastrointest. Liver Physiol. 307, 848-862. doi: 10.1152/ajpgi.00176.2014

Wu, L. L., Peng, W. H., Kuo, W. T., Huang, C. Y., Ni, Y. H., Lu, K. S., et al. (2014). Commensal bacterial endocytosis in epithelial cells is dependent on myosin light chain kinase-activated brush border fanning by interferon- $\gamma$. Am. J. Pathol. 184, 2260-2274. doi: 10.1016/j.ajpath.2014.05.003

Wu, Y. H., Zhang, X., and Wang, D. H. (2011). Role of asymmetric dimethylarginine in acute lung injury induced by cerebral ischemia/reperfusion injury in rats. J. South. Med. Univ. 31, 1289-1294.

Xiong, Y., Wang, J., Chu, H., Chen, D., and Guo, H. (2016). Salvianolic acid B restored impaired barrier function via downregulation of MLCK by microRNA1 in rat colitis model. Front. Pharmacol. 7:320. doi: 10.3389/fphar.2016. 00134

Xiong, Y. J., Chen, D. P., Lv, B. C., Liu, F. F., Wang, L., and Lin, Y. (2013). The characteristics of genistin-induced inhibitory effects on intestinal motility. Arch. Pharm. Res. 36, 345-352. doi: 10.1007/s12272-013-0053-2

Xu, C., Wu, X., Hack, B. K., Bao, L., and Cunningham, P. N. (2015). TNF causes changes in glomerular endothelial permeability and morphology through a Rho and myosin light chain kinase-dependent mechanism. Physiol. Rep. 3:e12636. doi: $10.14814 /$ phy2.12636

Yi, Z., Fan, H., Liu, X., Tang, Q., Zuo, D., and Yang, J. (2015). Adrenomedullin improves intestinal epithelial barrier function by downregulating myosin light chain phosphorylation in ulcerative colitis rats. Mol. Med. Rep. 12, 3615-3620. doi: $10.3892 / \mathrm{mmr} .2015 .3887$

Yi, Z. F., Fan, H., and Yang, J. (2014). Role of myosin light chain kinase in inflammatory bowel disease. World Chin. J. Digestol. 22, 5467-5472. doi: 10.11569/wcjd.v22.i35.5467

Yin, J., Wu, M., Duan, J., Liu, G., Cui, Z., Zheng, J., et al. (2015). Pyrrolidine dithiocarbamate inhibits NF-KappaB activation and upregulates the expression of Gpx1, Gpx4, occludin, and ZO-1 in DSS-induced colitis. Appl. Biochem. Biotechnol. 177, 1716-1728. doi: 10.1007/s12010-015-1848-Z

Yu, Q. H., Guo, J. F., Chen, Y., Guo, X. R., Du, Y. Q., and Li, Z. S. (2016). Captopril pretreatment protects the lung against severe acute pancreatitis induced injury via inhibiting angiotensin II production and suppressing Rho/ROCK pathway. Kaohsiung J. Med. Sci. 32, 439-445. doi: 10.1016/j.kjms.2016. 07.008

Zerem, E. (2014). Treatment of severe acute pancreatitis and its complications. World J. Gastroenterol. 20, 13879-13892. doi: 10.3748/wjg.v20.i38. 13879

Zhang, H. L., Tang, Z. Y., Yang, J. X., Zhang, Y., Li, Y., and Lin, Y. (2006). Bi-directional regulation of emodin and quercetin on smooth muscle myosin of gizzard. FEBS Lett. 580, 469-473. doi: 10.1016/j.febslet.2005. 12.041

Zhang, Y. S., Liu, B., Luo, X. J., Li, T. B., Zhang, J. J., Peng, J. J., et al. (2015). Nuclear cardiac myosin light chain 2 modulates NADPH oxidase 2 expression in myocardium: a novel function beyond muscle contraction. Archiv Für Kreislaufforschung 110:494. doi: 10.1007/s00395-0150494-5 
Zhou, T., Wang, T., and Garcia, J. G. (2014). Genes influenced by the non-muscle isoform of Myosin light chain kinase impact human cancer prognosis. PLoS ONE 9:e94325. doi: 10.1371/journal.pone.0094325

Zhou, T., Wang, T., and Garcia, J. G. (2015). A nonmuscle myosin light chain kinase-dependent gene signature in peripheral blood mononuclear cells is linked to human asthma severity and exacerbation status. Pulmonary Circulation 5, 335-338. doi: 10.1086/680357

Zhu, H. Q., Wang, X. B., Han, J. X., Hu, Z. P., Wang, Y., Zhou, Q., et al. (2013). Myosin light chain kinase inhibitor attenuates atherosclerosis and permeability via reduced endothelial tight junction in rabbits. Int. J. Cardiol. 168, 5042-5043. doi: 10.1016/j.ijcard.2013.07.219
Conflict of Interest Statement: The authors declare that the research was conducted in the absence of any commercial or financial relationships that could be construed as a potential conflict of interest.

Copyright (c) 2017 Xiong, Wang, Shi, Wang, Zhou, Chen, Wang and Guo. This is an open-access article distributed under the terms of the Creative Commons Attribution License (CC BY). The use, distribution or reproduction in other forums is permitted, provided the original author(s) or licensor are credited and that the original publication in this journal is cited, in accordance with accepted academic practice. No use, distribution or reproduction is permitted which does not comply with these terms. 